\title{
Change of Individual Weight of a Patient with Autoimmune Thyroiditis and Colon Cancer Before and After Treatment
}

ISSN: 2637-773X

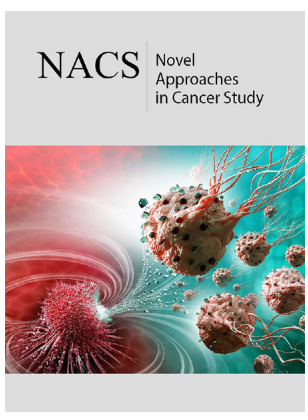

*Corresponding author: Zotin AA, NK Koltsov Institute of Developmental Biology, Moscow, Russia

Submission: 睯 September 19, 2019

Published: 制October 24, 2019

Volume 3 - Issue 2

How to cite this article: Zotin A. Change of Individual Weight of a Patient with Autoimmune Thyroiditis and Colon Cancer Before and After Treatment. Nov Appro in Can Study. 3(2). NACS.000566.2019. DOI: 10.31031/NACS.2019.03.000566

Copyright@ Zotin AA, This article is distributed under the terms of the Creative Commons Attribution 4.0 International License, which permits unrestricted use and redistribution provided that the original author and source are credited.

\section{Zotin AA*}

NK Koltsov Institute of Developmental Biology, Russia

\begin{abstract}
Human growth, as a rule, is studied in the youthful period, limited to the first 20-30 years of life. This is largely due to the fact that a person's linear growth in height ends by 18-22 years old Bogin [1]. A person's weight reaches a maximum by 25-30 years Zotin [2]. However, a change in body mass occurs throughout life. In addition, growth is usually accompanied by biorhythms even during periods when changes in average body weight are not observed. The initial goal of the work was to identify growth biorhythms in adults measuring my weight for example. However, during the study, diseases that affect body weight were discovered. Accordingly, the purpose of the work has changed.
\end{abstract}

\section{Materials and Methods}

I took measurements of my own weight on a floor scale with an accuracy of $100 \mathrm{~g}$, starting from the age of 21,748 days ( $\approx 59.6$ years) daily. The start date of measurements (26 September 2014) is taken as 0. The last date was 18 September 2019 (1842 days after the start of measurement; $\approx 5.0$ years). Autoimmune thyroiditis was diagnosed on day 557 (05 April 2016). Treatment with sodium levothyroxine (Eutiroks, Merck KGaA, Darmstadt, Germany) was prescribed. Drug regimen was daily intake of $100 \mathrm{mg}$. Treatment started from 569 day. The dose was increased to $150 \mathrm{mg}$ starting from 1251 day. Monitoring of the course of treatment was carried out by analyzing the blood levels of free triiodothyronine, free thyroxine, thyroid-stimulating hormone, antibodies to thyroglobulin, antibodies to thyroid pyroxidase.

On day 1498 an operation (laparotomy) was performed according to the results of which cancer of the rectosigmoid colon was diagnosed. From 1540 days a course of chemotherapy was started according to the following scheme. Intravenous administration of bevacizumabi ("BIOCAD", Russia) at a dose of 800mg, oxaliplatini ("EBEWE Pharma", Russia) at a dose of $100 \mathrm{mg}$, ondansetron ("Sotex Pharmfirm", Russia) at a dose of $16 \mathrm{mg}$ on the first day. Oral administration of capecitabini ("Pharmasyntez-Nord", Russia) fFrom the day 2 to the day 15. Medicines are not accepted from the day 16 to the day 21. This pattern is repeated continuously. Monitoring of the course of treatment was carried out using computed tomography. Biorhythms were detected by singular spectrum analysis using Caterpillar-SSA software (version 3.40, by Gista T Group, Russia).

Results

The study of changes in body weight can be divided into three periods.

1) Without treatment (0-568 days).

2) Treatment for autoimmune thyroiditis (569-1539 days).

3) Treatment for autoimmune thyroiditis and chemotherapy (1540-1818 days) (Figure 1).

During the first stage body weight tends to remain constant. The figure shows distinct growth biorhythms in this stage. A singular spectral analysis shows that five regular biorhythms can be distinguished, the period and amplitude of which remain constant. 
a) Biorhythm with a period of $\approx 0.5$ years (period $\mathrm{P}=198 \pm 24$ days; amplitude $A=0.99 \pm 0.15 \mathrm{~kg}$ ).

b) Biorhythm with a period of about a month $(\mathrm{P}=31.1 \pm 2.1$ days; $A=0.30 \pm 0.04 \mathrm{~kg}$ ).

c) Biorhythm with a period of $\approx 3$ weeks $(\mathrm{P}=21.3 \pm 1.2$ days; $A=0.13 \pm 0.01 \mathrm{~kg}$ ).

d) Biorhythm with a period of $\approx 2$ weeks $(\mathrm{P}=14.3 \pm 0.2$ days; $A=0.17 \pm 0.01 \mathrm{~kg}$ ).

e) Biorhythm with a period of about a week $(\mathrm{P}=7.1 \pm 0.1$ days; $A=0.24 \pm 0.01 \mathrm{~kg}$ ).

Whether these biorhythms are endogenous or exogenous remains unclear. The change in body weight in the second and third stages is shown in the (Figure 1). Despite changes in body weight, all five biorhythms persist at these stages. However, the amplitude of these biorhythms varies. The pattern of the amplitude changes is not clear. Of course, data based on a single case is not enough for any conclusions about the patterns of human growth in normal and pathological conditions. However, the proposed data may provide the basis for further research.

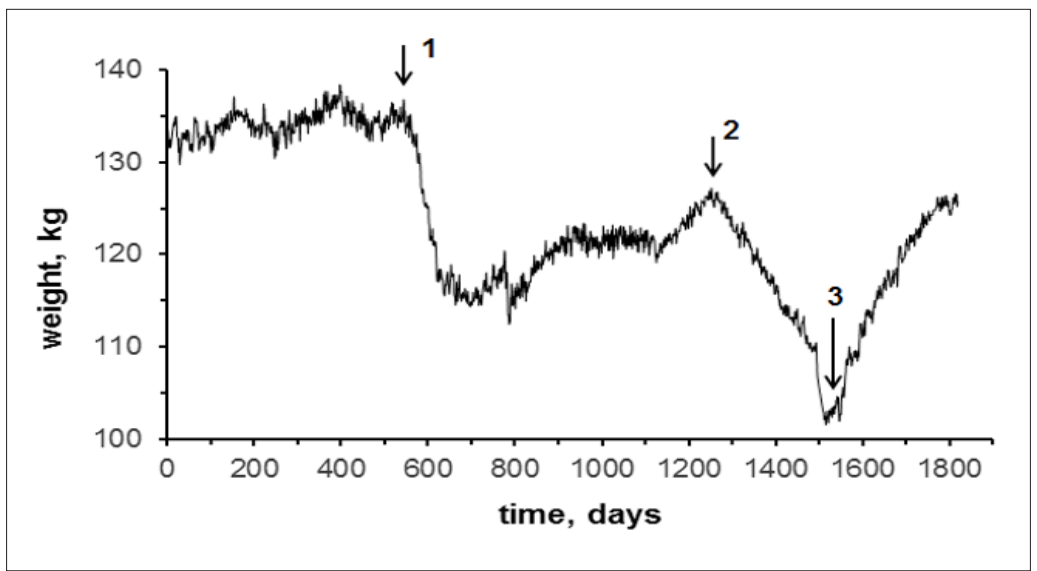

Figure 1: Body weight dependence on the period from the start of the measurement. Arrows:

1 - start of treatment with sodium levothyroxine at a dose of 100mg/day;

2 - dose of sodium levothyroxine changed by $150 \mathrm{mg} /$ day; 3 - the beginning of chemotherapy.

\section{Acknowledgment}

The author is grateful to the doctors of Dorzhiev S.D. (endocrinologist) and Dr. Polyansky M.A. (oncologist) for the appointment and treatment. The study was conducted as part of the state program of basic scientific research of the Koltzov Institute of Developmental Biology, Russian Academy of Sciences, no. 01082019-0003.

\section{References}

1. Bogin B (2015) Human growth and development. In: Michael $P$ Meuhlenbein (Ed.), Basics in Human Evolution, London: Academic Press, USA, pp. 285-293.

2. Zotin AA (2006) Equations describing changes in weight and massspecific rate of oxygen consumption in animals during postembryonic development. Biology Bulletin 33(4): 323-331. 